\title{
New Records of the Ogilvie Mountains Collared Lemming (Dicrostonyx nunatakensis) in central Yukon
}

\author{
Thomas S. Jung ${ }^{1,4}$, Brian G. Slough ${ }^{2}$, David W. NAgOrsen ${ }^{3}$, and PiIA M. KuKKa ${ }^{1}$ \\ ${ }^{1}$ Yukon Department of Environment, Box 2703, Whitehorse, Yukon Y1A 2 C6 Canada \\ 235 Cronkhite Road, Whitehorse, Yukon Y1A 5S9 Canada \\ ${ }^{3}$ Mammalia Biological Consulting, Victoria, British Columbia V9C $3 Z 4$ Canada \\ ${ }^{4}$ Corresponding author: thomas.jung@gov.yk.ca
} Jung, Thomas S., Brian G. Slough, David W. Nagorsen, and Piia M. Kukka. 2014. New records of the Ogilvie Mountains Col-
lared Lemming (Dicrostonyx nunatakensis) in central Yukon. Canadian Field-Naturalist 128(3): 265-268.

The Ogilvie Mountain Collared Lemming (Dicrostonyx nunatakensis Youngman, 1967), reported only from the Ogilvie Mountains of central Yukon, is among the least known mammals in Canada. It was first discovered in 1961 and, since then, only 13 specimens had been collected, all from one mountain, in central Yukon. We conducted a targeted survey to determine the distribution of the species by trapping areas of apparently suitable habitat on 12 mountains within $40 \mathrm{~km}$ of the known location. Many of our traps were disabled by other mammals; however, we captured three Ogilvie Mountain Collared Lemmings on two mountains $25.9 \mathrm{~km}$ and $29.6 \mathrm{~km}$ from the original location. Our findings suggest that this lemming may be more widely distributed than indicated by earlier specimens. We suggest further surveys to delineate the range of the Ogilvie Mountain Collared Lemming.

Key Words: Ogilvie Mountain Collared Lemming; Dicrostonyx nunatakensis; distribution; Tombstone Territorial Park; Yukon

\section{Introduction}

The Ogilvie Mountain Collared Lemming (Dicrostonyx nunatakensis Youngman, 1967) is known from only one mountain in central Yukon, Canada. Collared Lemmings in the Ogilvie Mountains are geographically separated from populations of Nearctic Collared Lemming (Dicrostonyx groenlandicus) to the northeast by about $250 \mathrm{~km}$ of apparently unoccupied habitat. The nearest recorded population of Nearctic Collared Lemming is in the Richardson Mountains, northeast of the Ogilvie Mountains. Youngman (1967) speculated that Collared Lemmings in the Ogilvie Mountains represent a relic population of Dicrostonyx that became isolated on nunataks (unglaciated mountain tops) during the Last Glacial Maximum and that they may remain reproductively isolated. Although the Ogilvie Mountain Collared Lemming is afforded species status by Wilson and Reeder (2005), the taxonomic status of Collared Lemmings in the Ogilvie Mountains is unresolved (J. Eger, Royal Ontario Museum, personal communication).

The Ogilvie Mountain Collared Lemming is one of the least known terrestrial mammals in North America (Nagorsen 1998). Only 13 museum specimens exist, all collected from a single mountain, Trapper Mountain $\left(64.583^{\circ},-138.217^{\circ}\right)$, located in Tombstone Territorial Park, Yukon (Youngman 1964, 1967, 1975; Slough and Jung 2007). The specimens were collected at 1625 $1676 \mathrm{~m}$ above sea level in dry rocky alpine tundra (heath) at the base of glacial cirques.

Limited survey effort has hampered our ability to assess accurately the distribution of this apparently range-restricted small mammal. Because surveys have been constrained by the remote high-elevation habitats in the Ogilvie Mountains, it is unknown whether this species is restricted to a single mountain. We con- ducted a targeted survey for the Ogilvie Mountain Collared Lemming to determine whether it inhabits other nearby mountains. This information is essential for better understanding the distribution and conservation status of this population.

\section{Study Area}

During 19-31 August 2011, we surveyed 12 mountains in the southern Ogilvie Mountains, all located within Tombstone Territorial Park. Tombstone Territorial Park is approximately $2,200 \mathrm{~km}^{2}$, much of which lies above the tree line. Our sampling sites were distributed over five distinct mountain ranges (Table 1 and Figure 1). The mountains we surveyed were distributed throughout the park to provide spatial coverage of the alpine habitat within the park. We did not sample at Trapper Mountain because the species was already known from there (Youngman 1964, 1967, 1975; Slough and Jung 2007). Survey sites were accessed by helicopter.

\section{Methods}

On each mountain surveyed, we selected a sampling site in alpine tundra that was similar in elevation and habitat characteristics (dry heath, gentle slope) to capture sites on Trapper Mountain (Youngman 1975; Jung et al., unpublished data). At each sampling site, we set snap-traps in variable-length trap lines that contained 60 trapping stations (49 in 1 case) set $10-15 \mathrm{~m}$ apart. At each trapping station, we set both a Museum Special and a Victor snap-trap (Woodstream Corp., Lititz, Pennsylvania) 1-2 m apart. Traps were baited with peanut butter and rolled oats and left unattended for 9-11 days $(\overline{\mathrm{x}}=10.3 \pm 0.3$ standard deviation $[\mathrm{SD}]$; Table 1). We recorded the number of specimens captured per trap line and the number of traps that were 




Figure 1. Boundaries of Tombstone Territorial Park, Yukon, Canada, and the 12 sites sampled for the Ogilvie Mountains Collared Lemming (Dicrostonyx nunatakensis) in 2011. Filled circles indicate locations where lemmings were captured, open circles where they were not detected. Note: Trapper Mountain is the only mountain where specimens were previously collected.

sprung or not functioning at the end of the sampling period. Our sampling protocol represented a maximum sampling effort of 14638 trap nights ( 1 trap night $=1$ trap set for 1 night).

Captured animals were identified by morphology and pelage. Small mammals were identified using the key provided by MacDonald (2003). Identification of the Ogilvie Mountains Collared Lemming was based on morphologic and pelagic characteristics, particularly very short tail and ears, densely furred feet, and buff-gray fur with a black dorsal stripe (MacDonald 2003). We deposited specimens at the Royal Ontario Museum (Toronto, Ontario).

\section{Results and Discussion}

Overall the number of animals captured was small: 26 captures of small mammals of four species, including three specimens of the Ogilvie Mountains Collared Lemming (Table 1). Ogilvie Mountains Collared Lemmings were collected from two of the 12 mountains surveyed, both in the Seela Range (Table 1). The two sites were $5.7 \mathrm{~km}$ apart and $25.9 \mathrm{~km}$ and $29.6 \mathrm{~km}$ west of previous collections on Trapper Mountain. Capture locations were among the most distant sampling sites from Trapper Mountain, and they were separated from

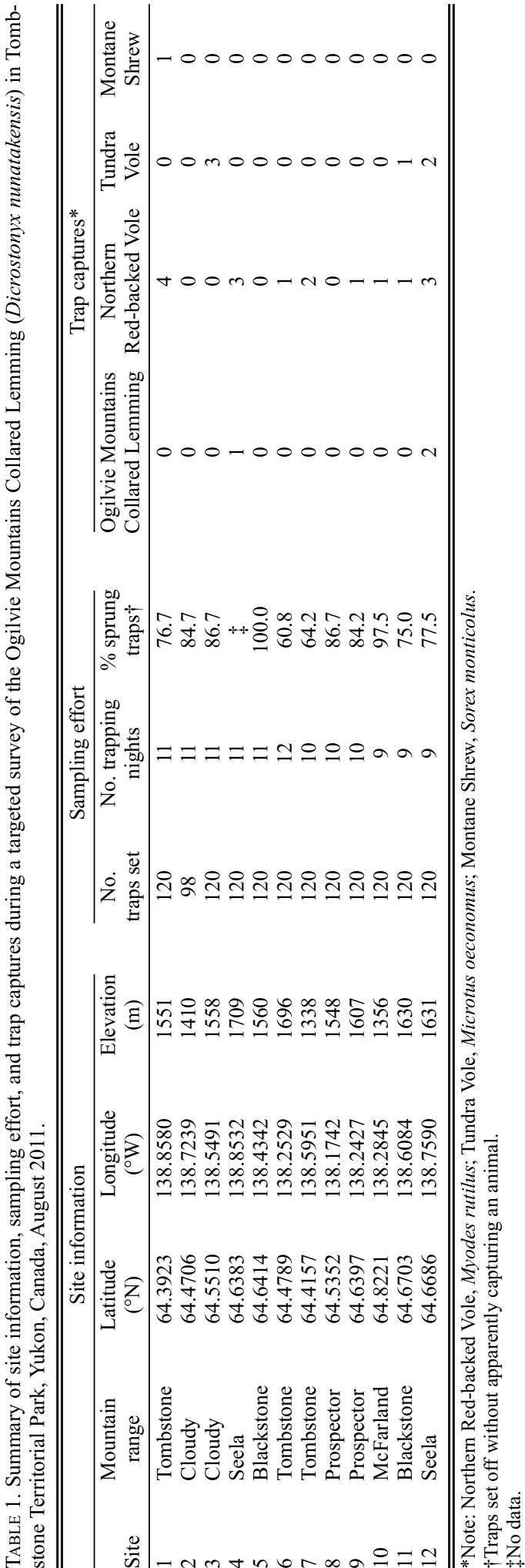


Trapper Mountain by the Blackstone River, a potential barrier to dispersal (Figure 1).

Two Ogilvie Mountains Collared Lemmings were juvenile males and the other was a juvenile female. They were collected in dry heath type habitat at elevations (1631-1709 m above sea level; Figure 2) typical of previous captures at Trapper Mountain (Youngman 1967; Slough and Jung 2002). Vegetation at the capture sites was dominated by mountain avens (Dryas spp.), dwarf willow (Salix spp.), mosses, lichens (Thamnolia vermicularis, Flavocetraria nivalis), and grasses (e.g., Anthoxanthum monticola), along with other ericaceous species (e.g., Arctous alpinus, Betula glandulosa, Empetrum nigrum, Cassiope tetragona, Vaccinium vitis-idaea; Figure 2). Small mammal species caught in association with the Ogilvie Moun-
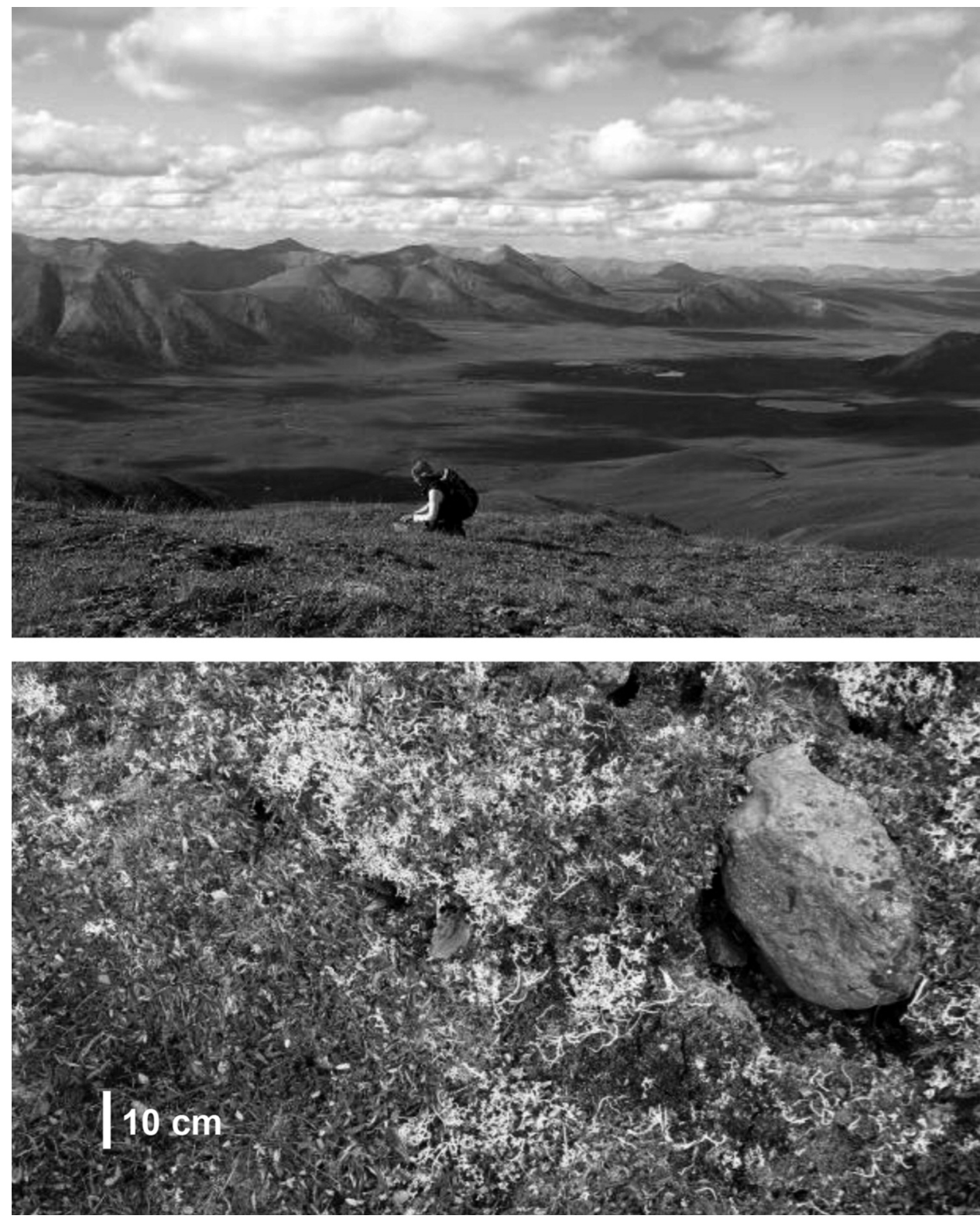

FIGURE 2. Landscape (top) and micro-site (bottom) views of the high alpine heath habitat where the Ogilvie Mountains Collared Lemming (Dicrostonyx nunatakensis) was collected in central Yukon, Canada, August 2011. Scale shown in the bottom panel is approximate. Photos: Brian Slough (top) and Thomas Jung (bottom). 
tains Collared Lemming were the Northern Red-backed Vole (Myodes rutilus), the Tundra Vole (Microtus oeconomus), and the Montane Shrew (Sorex monticolus; Table 1).

Many traps $(\overline{\mathrm{x}}=81.2 \% \pm 3.7 \% \mathrm{SD})$ were prematurely sprung or missing when we returned to check them (Table 1), which substantially reduced the sampling effort. Based on earlier survey work using the same trapping protocol in the study area (Jung et al., unpublished data), we suspect that most traps were disabled early within the sampling period, resulting in the low number of small mammals captured. However, the time from deployment during which our traps were functional is unknown. Arctic Ground Squirrels (Urocitellus parryii) were abundant at all sampling sites, and we suspect that they were responsible for the vast majority of traps that were prematurely sprung or missing. For further surveys, means should be sought to reduce disturbance of traps by Arctic Ground Squirrels, such as placing a wire enclosure over the trap.

We confirm that Ogilvie Mountains Collared Lemmings are more widely distributed than solely on Trapper Mountain. We suspect that they were present on some of the 10 mountains we surveyed without detecting them. The habitat at all sites surveyed was similar. The functional loss of many traps likely resulted in a low sampling effort, hindering our ability to capture collared lemmings at some survey sites. The occurrence of Ogilvie Mountains Collared Lemmings on three mountains within the Ogilvie Mountains suggests that they may be somewhat widespread in suitable habitats there. Moreover, Youngman (1975) speculated that the Ogilvie Mountains Collared Lemming likely also occurs in the adjacent Wernecke and Selwyn Mountains of central Yukon, but there have been few (if any) small mammal surveys in these ranges. Further surveys are needed to delineate the range of the Collared Lemming within the Ogilvie Mountains and adjacent ranges.

\section{Acknowledgements}

We thank D. Amos, C. Eckert, and T. Powell for facilitating this work and assisting with field logistics. We thank L. Hughes, S. Hughes, M. Kienzler, and A. McCulley for field assistance. We thank J. Eger for discussions about collared lemmings and archiving our specimens at the Royal Ontario Museum. Two anonymous reviewers provided thoughtful comments on an earlier draft of this manuscript.

\section{Literature Cited}

MacDonald, S. O. 2003. The small mammals of Alaska: a field handbook of the shrews and small rodents. Unpublished manuscript. Accessed 20 September 2013. http:// science.nature.nps.gov/im/units/swan/assets/docs/reports /inventories/MacDonaldS 2003 AKRO SmallMammal HandbookCondensed_572288.pdf

Nagorsen, D. W. 1998. Dicrostonyx nunatakensis. Page 88 in North American Rodents: Status Survey and Conservation Action Plan. Edited by D. J. Hafner, E. Yensen, and G. L. J. Kirkland. IUCN Publications, Gland, Switzerland.

Slough, B. G., and T. S. Jung. 2007. Diversity and distribution of the mammals of the Yukon Territory: a review. Canadian Field-Naturalist 121: 119-127.

Wilson, D. E., and D. A. Reeder (editors). 2005. Mammal Species of the World. A Taxonomic and Geographic Reference. Third edition. The Johns Hopkins University Press, Baltimore, Maryland, USA. 2142 pages.

Youngman, P. M. 1964. Range extensions of some mammals from Northwestern Canada. Natural History Papers 23. National Museum of Canada, Ottawa, Ontario, Canada.

Youngman, P. M. 1967. A new subspecies of varying lemming, Dicrostonyx torquatus (Pallas), from Yukon Territory (Mammalia, Rodentia). Proceedings of the Biological Society of Washington 80: 31-34.

Youngman, P. M. 1975. Mammals of the Yukon Territory. Publications in Zoology 10. National Museum of Canada, Ottawa, Ontario. 192 pages.

Received 2 October 2013

Accepted 3 February 2014 